\title{
Development of Series Hydraulic Hybrid Drive Train with Regenerative Suspension for Heavy Duty Vehicles
}

\author{
Mayank Giri ${ }^{1}$, Renuka Sahu ${ }^{2}$ \\ ${ }^{1,2}$ Department of Mechanical Engineering, National Institute of Technology Raipur
}

\begin{abstract}
This paper presents the comparison of conventional model of series and parallel hydraulic hybrid vehicle in terms of efficiency and mechanism employed. A concept of a Hydraulic Hybrid Vehicle drive train to improve the fuel efficiency of heavy duty vehicles and urban transit buses is given. The developed series hydraulic hybrid drive train enables to use the energy lost in Breaking and Suspension. The Energy Flow equations for components of the drive train are shown. A break-even analysis of modified hydraulic hybrid vehicle with percentage improvement in mileage and decrease in fuel cost has been shown. The series hydraulic hybrid system exhibits potential for excellent fuel economy. The increase in mileage has been depicted using calculations. The developmental work in the area of high efficiency pump/motor is required for further improvements.
\end{abstract}

Keywords: HHV, BBL/D, EPA, MPG, HEV

\section{Introduction}

Transportation is a major component of global energy consumption. Only transportation sector consumes 13.8 million $\mathrm{bbl} / \mathrm{d}$ as of $2013[1]$.

Current scenario of fossil fuel- a The amount of years of fossil fuel left in the world is as follow [2]-

Oil- 35 years Coal- 107 years Gas - 37 years These alarming statistics are the motivation for the development of Hydraulic Hybrid drive train that significantly improves the efficiency of the vehicle as well as helps in reducing the emissions.

The majority of previous work present in the literature involving Series Hydraulic Hybrid drive train did not include the use of energy lost in breaking as well as suspension. A project on HHV done by Environment Protection Agency (EPA) shows $60-70 \%$ mpg improvement in city driving [3]. The focus of the paper is the Series Hydraulic Hybrid drive train. This system aims to utilize the power recovered from the suspension and breaking in order to increase efficiency and reduce fuel consumption.

\section{Hybrid Vehicle}

Any vehicle that combines two or more power sources that can directly or indirectly provide propulsion is a hybrid. Two auxiliary power sources have been found most practical: electric motor/generator combined with batteries and hydraulic pump/motors combined with hydraulic accumulators.

Hybrid Electric Vehicles (HEV) are being commercially produced. The shortcoming of HEV is the relatively low power density of both motor/generator and batteries at approximately $30-100 \mathrm{~W} / \mathrm{kg}$ [4].
1) The power density of hydraulic pumps/motors and hydraulic accumulators is very high at approximately 500 $1000 \mathrm{~W} / \mathrm{kg}$ [4].

2)Hydraulic components are less expensive then electrical components.

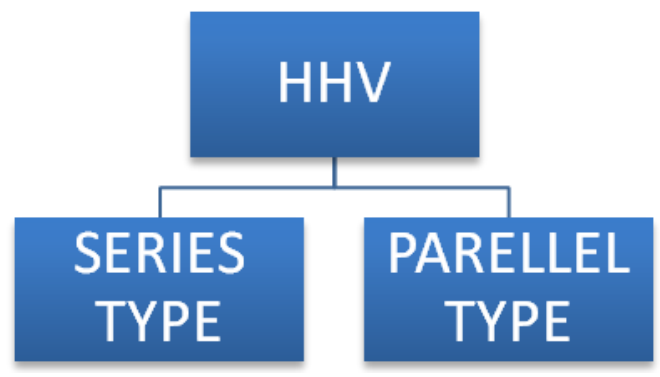

2.1 Series Type

In this type of HHV the Internal Combustion Engine is used to run a motor which is connected to an accumulator and a pump/motor. The hydraulic pump pressurizes the low pressure fluid to the pump/motor to provide required torque to turn the axle. Any excess high pressure fluid produced by the engine pump is stored in the high pressure accumulator. When acceleration is required the saved energy in high pressure accumulator provides the torque to turn the axle. With the ability to shut off the engine, series hydraulic hybrids are estimated to improve fuel economy by 60 to 70 percent [3]. 


\section{International Journal of Science and Research (IJSR) \\ ISSN (Online): 2319-7064}

Index Copernicus Value (2013): 6.14 | Impact Factor (2015): 6.391

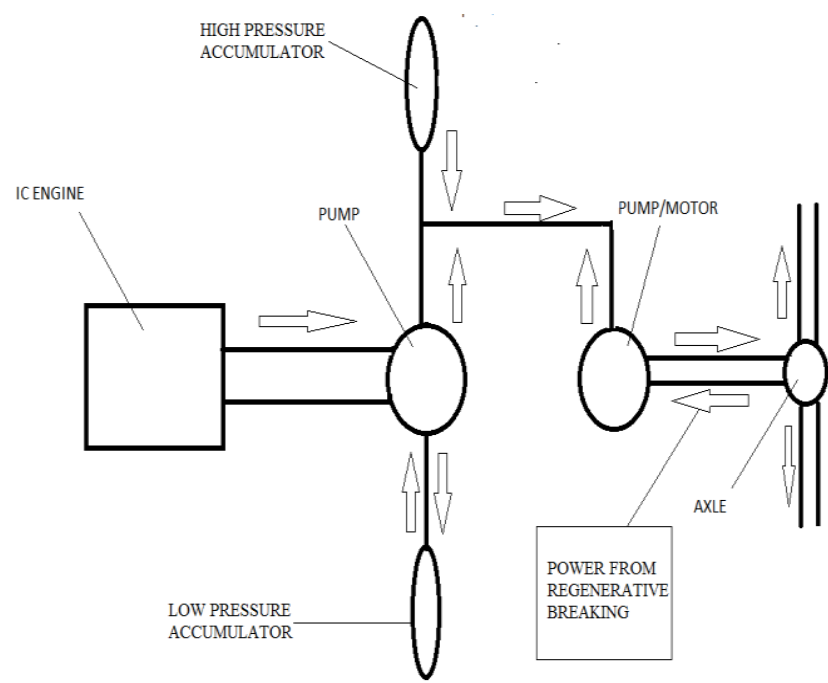

Figure 1: Hydraulic Hybrid Series drive train. Double lines represent shaft coupling while single lines represents hydraulic coupling.

\subsection{Parallel Type}

In this type of HHV the hydraulic components are simply connected to conventional transmission and drive shafts. This allows the system to assist the engine in acceleration, but it does not allow the engine to shut off, when power is not required. This leads to a lesser fuel economy than of the Series type.

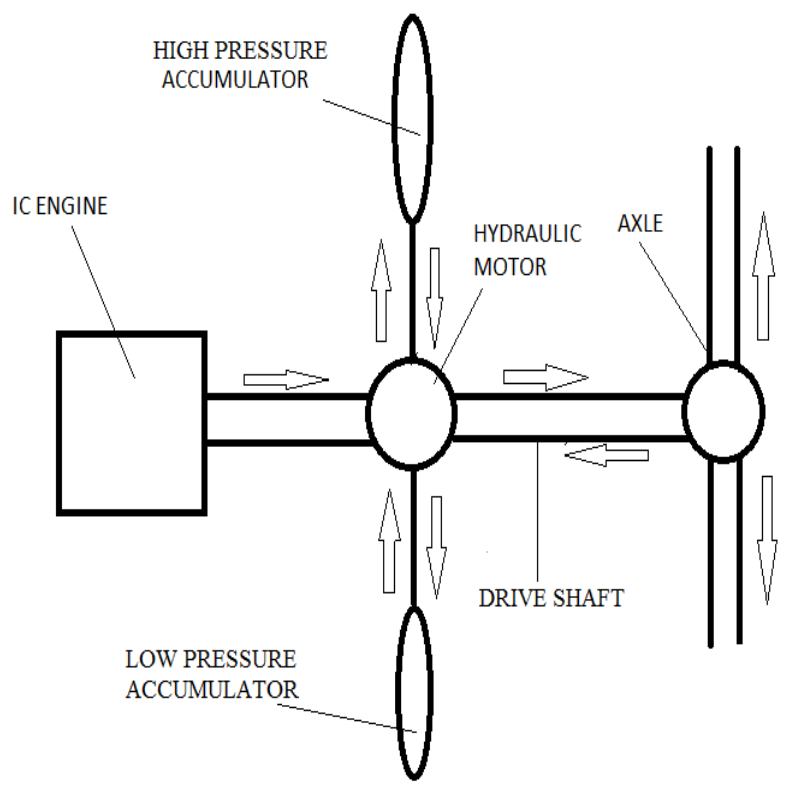

Figure 2: Hydraulic Hybrid Parallel drive train. Double lines represent shaft coupling while single lines represents hydraulic coupling.

\subsection{Comparison of Parallel \& Series Drive train}

The comparison between a Series hydraulic hybrid vehicle and a Parallel hydraulic hybrid is shown in the Table 1.
Table 1: Comparison between Series hydraulic hybrid and Parallel hydraulic hybrid

\begin{tabular}{|c|c|c|}
\hline Properties & Series $\mathrm{HHV}$ & Parallel HHV \\
\hline Efficiency & Higher & Lower \\
Fuel consumption & Lower & Higher \\
Emissions & Less & High \\
Cost effective & More & Less \\
Brake Wear & Lower & Higher \\
Engine on-time & Lower & Higher \\
\hline
\end{tabular}

Thus we see that the series HHV gives us various advantages like greater efficiency and reduced emissions over the parallel type. In series type the engine can be shut off completely while idling and also while braking and power cruising, thereby reducing emissions significantly. It gives highest possible fuel economy with low incremental cost and highest possible savings. According to the requirements the series HHV greatly reduces fuel consumption and greenhouse gases. Series type is equally competent by both environmental and economic terms and is hence preferred over parallel type HHV.

\section{Modified Series Drive train Model}

To understand the concept and modification, a diagram of the system is provided in the Figure 3. The figure is annotated with numbers in balloons and arrows to define the positive power flow direction between the components.

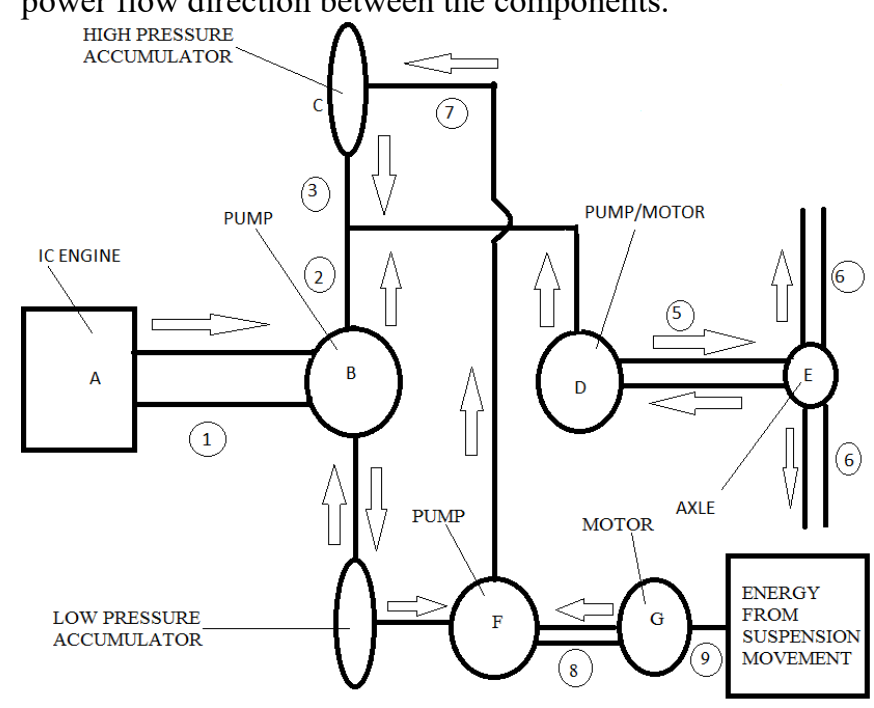

Figure 3: Modified Series Hydraulic Hybrid drive train. Double lines represent shaft coupling while single lines represents hydraulic coupling.

\subsection{Working}

\subsubsection{Regenerative Breaking}

While the Engine A is running, it supplies the power to the Motor B, which pressurizes the fluid from low pressure accumulator to the Pump/Motor D. Further Pump/Motor D provides torque to turn the axle. The excess high pressure fluid is transferred to the high pressure Accumulator. While accelerating the energy stored in the high pressure accumulator is used to propel the vehicle.

While breaking, the Pump/Motor D works as Pump and transfer the fluid from low pressure reservoir to high pressure 


\section{International Journal of Science and Research (IJSR) \\ ISSN (Online): 2319-7064}

Index Copernicus Value (2013): 6.14 | Impact Factor (2015): 6.391

accumulator. Thus, the energy generally lost in breaking is used to propel the vehicle.

\subsubsection{Regenerative Suspension}

A Regenerative suspension system based upon a hydraulic ram that replaces a standard shock absorber where the up and down movements of the suspension system drives an external hydraulic pump, which pressurizes the hydraulic fluid to the high pressure accumulator. Thus, the energy lost in suspension system is recovered and stored in the high pressure accumulator in the form of pressurized liquid. The energy stored in the high pressure accumulator is used to propel the vehicle.

To understand the working of Regenerative Suspension a conceptual diagram is provided in Figure 4.

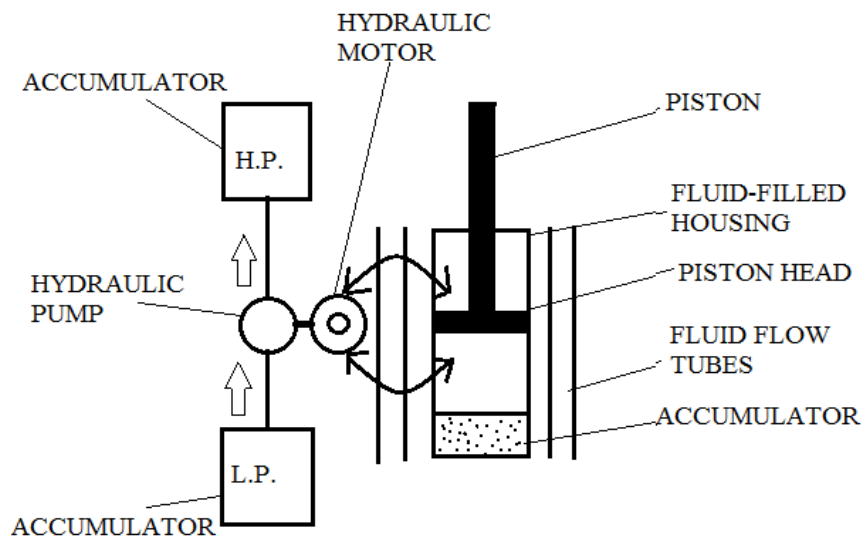

Figure 4: Schematic representation of Regenerative Suspension system. L.P. stands for Low Pressure and H.P. stands for High Pressure.

The Piston is disposed in Fluid-filled housing. When the vertical motion occurs because of the bump on the road, the piston moves in downward direction and forces the fluid into the Fluid flow tubes. These Fluid flow tubes allows communication between the Piston Head and the Hydraulic Motor. When piston moves downward and forces the fluid into the fluid-filled tubes, the movement of the fluid results in the rotation of the hydraulic motor. The hydraulic motor is coupled with a hydraulic pump, which connects the low pressure accumulator to the high pressure accumulator. As the hydraulic motor rotates due to the shock created by a bump on the road, because of the coupling, the hydraulic pump also rotates and pressurize fluid from low pressure accumulator to the high pressure accumulator. An accumulator at the end of the stroke is provided to compensate the increase in volume of the fluid-filled housing because of the piston rod volume.

It is required that the hydraulic motor operates in a single direction. For this an electronically controlled valve system with check valves is proposed. The check valves ensure that the fluid is not returned to the pump to back-drive it. When open, Electronically controlled valve system allows the fluid to pass through to it to the compression volume. The compression volume is in selective fluid communication through a check valve to the extension volume. When the piston is compressed, fluid flows from the compression volume to the extension volume, but flow cannot go in the opposite direction. The compression volume is also connected through a second electronically controlled valve to both the input port of the hydraulic motor and an accumulator that is sized to be at least large enough to accommodate the piston rod volume introduced during a compression stroke [5].

\subsection{Component Energy Equations}

The energy equations of power flow for the components in the drive train are developed. The power flow from the Engine A, Pump B and Pump F is always positive or zero. The power flow for all the other components can be either positive or negative. For example Pump/Motor D either works as a Motor while propelling the vehicle or acts as Pump while slowing the vehicle (breaking).Pump/Motor D while acting as a motor the power flow at 5 is equal to power flow at 4 multiplied by the motoring efficiency of the component. On the other hand, while acting as a pump the power flow at 4 is equal to power flow at 5 multiplied by the pumping efficiency of the unit. The power flow equations for all the other components can be found in Table 2.

Table 2: Power flow equations for modified series hybrid drive train

\begin{tabular}{|c|c|c|c|c|}
\hline \multirow{3}{*}{\begin{tabular}{|c|} 
Component \\
Pump B
\end{tabular}} & \multirow{2}{*}{\multicolumn{2}{|c|}{ Port }} & \\
\hline & & & \multirow{2}{*}{ Mode } & \multirow[t]{2}{*}{ Power Equation } \\
\hline & 1 & 2 & & \\
\hline & + & + & Pumping & $\mathrm{P}_{2}=\mathrm{P}_{1} \Pi_{\mathrm{B}, \text { pump }}$ \\
\hline \multirow{3}{*}{$\begin{array}{c}\text { Accumulator } \\
\mathrm{C}\end{array}$} & 3 & 7 & & \\
\hline & + & & Discharging & $\begin{array}{c}\mathrm{E}_{\mathrm{C}}=\mathrm{E}_{\mathrm{C}, \mathrm{prev}}- \\
\frac{P_{3}}{\eta_{C}} \Delta t\end{array}$ \\
\hline & - & + & Charging & $\begin{array}{c}\mathrm{E}_{\mathrm{C}}=\mathrm{E}_{\mathrm{C}, \text { prev }}- \\
\mathrm{P}_{3} \eta_{\mathrm{c}} \Delta \mathrm{t}+\mathrm{P}_{7} \eta_{\mathrm{C}} \Delta \mathrm{t}\end{array}$ \\
\hline \multirow{3}{*}{$\begin{array}{l}\text { Pump/ } \\
\text { Motor D }\end{array}$} & 4 & 5 & & \\
\hline & + & + & Motoring/Generating & $\mathrm{P}_{5}=\mathrm{P}_{4} \prod_{\mathrm{D}, \text { motor }}$ \\
\hline & - & - & Pumping/Regenerating & $\mathrm{P}_{5}=\frac{P_{4}}{\eta_{D, \text { Pump }}}$ \\
\hline \multirow{3}{*}{\begin{tabular}{|c} 
Axle \\
Differential \\
E
\end{tabular}} & 5 & 6 & & \\
\hline & + & + & Generating & $\mathrm{P}_{6}=\mathrm{P}_{5} \eta_{\mathrm{E}}$ \\
\hline & - & - & Regenerating & $\mathrm{P}_{6}=\frac{P_{5}}{\eta_{E}}$ \\
\hline \multirow[t]{2}{*}{ Pump F } & 7 & 8 & & \\
\hline & + & + & Pumping & $\mathrm{P}_{7}=\mathrm{P}_{8} \Pi_{\mathrm{F}}$ \\
\hline \multirow[t]{2}{*}{ Motor $\mathrm{G}$} & 8 & 9 & & \\
\hline & + & + & Motoring & $\mathrm{P}_{8}=\mathrm{P}_{9} \prod_{\mathrm{G}}$ \\
\hline \multicolumn{5}{|c|}{$\begin{array}{l}\text { Symbols } P_{i}-\text { Power flow through into or out of each component } \\
\text { where i refers to the balloons } \\
\qquad \eta_{\mathrm{j}}-\text { Power conversion efficiency of component } \mathrm{j} \text {. } \\
E_{k}-\text { Energy contained in component } \mathrm{k} \text {. } \\
\text { Generating and regenerating refers to applying positive or negative } \\
\text { power to the wheels. Charging and discharging refers to adding or } \\
\text { removing energy from the accumulator. For pump } \mathrm{F} \text { the flow is } \\
\text { positive in the direction shown in the figure. }\end{array}$} \\
\hline
\end{tabular}

\section{Fuel Efficiency Calculations}

\subsection{Regenerative Breaking}

A normal transit bus gives an average mileage of $4 \mathrm{~km} / \mathrm{l}-5$ $\mathrm{km} / \mathrm{l}$. A series hydraulic hybrid improves the fuel economy 


\section{International Journal of Science and Research (IJSR) \\ ISSN (Online): 2319-7064 \\ Index Copernicus Value (2013): 6.14 | Impact Factor (2015): 6.391}

by $60 \%-70 \%$ [3]. We are taking an average fuel saving of $65 \%$ to assist our calculation.

So now the improved mileage of series hydraulic hybrid becomes $(0.65 * 4+4=6.6) \mathrm{km} / \mathrm{l}$ to $(0.65 * 5+5=8.25) \mathrm{km} / \mathrm{l}$ I.e. $6.6 \mathrm{~km} / 1$ to $8.25 \mathrm{~km} / 1$

\subsection{Regenerative Suspension}

We have used regenerative suspension in modified series hydraulic hybrid drive train. A group of MIT students developed the model of regenerative suspension and estimated a fuel saving of $10 \%$ [5]. So by using the modified drive train, the fuel saving due to regenerative breaking and regenerative suspension becomes

\section{$7.3-9.08 \mathrm{~km} / \mathrm{l}$}

\section{Cost Efficiency Calculations}

Cost of modification $=$ Rs 3,75,000 Assuming the mileage to be constant over years, Mileage of a normal heavy duty vehicle $=4.5 \mathrm{~km} / 1$ Mileage of proposed $\mathrm{HHV}=8.2 \mathrm{~km} / 1$

Assuming the price of diesel to be constant over years, Cost of Diesel (Approx.) = Rs 46 per litre A heavy duty vehicle is driven on an average $17000 \mathrm{~km}$ per year.

Cost of diesel for a normal heavy duty vehicle $=$ Rs $1,73,770$ Cost of diesel for the proposed HHV = Rs 95.370 Amount of money saved per year $=$ Rs 78,400 Time required for the modification cost to made up $=4$.8years

\section{Comparison Table}

\begin{tabular}{|c|c|c|c|}
\hline & $\begin{array}{c}\text { Normal } \\
\text { Vehicle }\end{array}$ & $\begin{array}{c}\text { Proposed } \\
\text { HHV }\end{array}$ & $\begin{array}{c}\text { Mileage } \\
\text { Improvement (\%) }\end{array}$ \\
\hline Mileage (km/l) & 4.5 & 8.2 & 82.22 \\
\hline & & & Cost Reduction (\%) \\
\hline Annual Fuel Cost (Rs) & $1,73,770$ & 95,370 & 45.11 \\
\hline
\end{tabular}

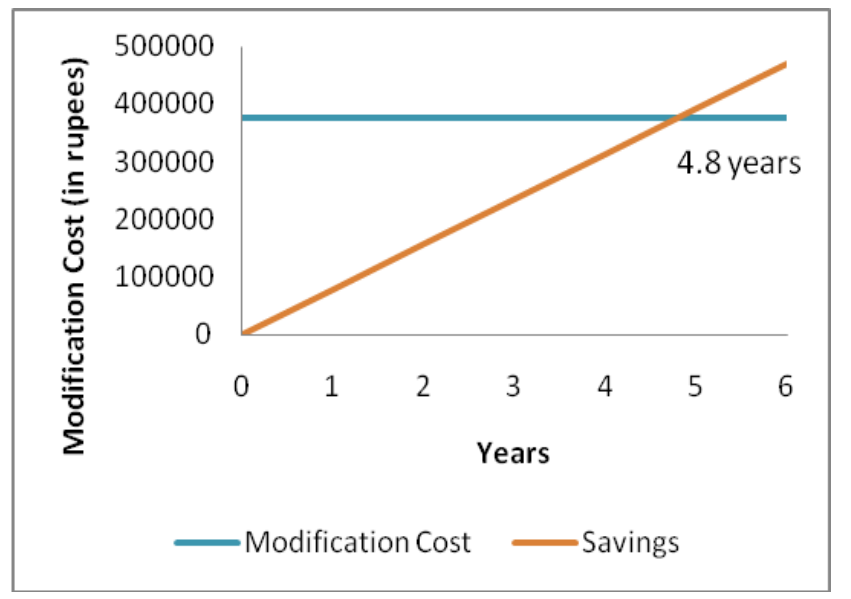

\section{Conclusion}

Since fossil fuels are running out at a tremendous rate it is the need of the hour to look for competent alternative technologies. Hybrid electric vehicles have been commercialized and are successful. The hydraulic components used in the HHV are less costly than the electrical batteries and motor used in the HEV, making it more cost effective. Also the increase in efficiency in HEV is $20-30 \%$ whereas in the HHV it is $60-70 \%$ [3], which makes it a better alternative technology. Yet there is a need of further work in the area of more efficient hydraulic pumps and motors.

\section{References}

[1] U.S. Energy Information Administration(EIA), "Annual Energy Outlook 2015 (AEO)," 9-13, DOE/EIA 0383(2015)|. [Online]. Available http://www.eia.gov/forecasts/aeo, [Accessed June 17, 2016].

[2] Shafiee, Shahriar, and Erkan Topal. "When will fossil fuel reserves be diminished?." Energy policy 37.1 (2009) : 181-189.

[3] Environment Protection Agency, United States (EPA), $5^{\text {th }}$ International Environmentally Friendly Vehicle Conference, Baltimore, Maryland, " Advanced Series Hydraulic Hybrid, Technology for Economic Growth and Sustainability," September 2012.

[4] Van de Ven, James D., Michael W. Olson, and Perry Y. Li. "Development of a hrdro-mechanical hydraulic hybrid drive train with independent wheel torque control for an urban passenger vehicle." Proceedings of the national conference on fluid power Vol. 51.

[5] Evans, Paul. "MIT Students develop Hydraulic Regenerative Shock Absorbers," (2009)

[6] Tarun Kaushik, and Nilay Pandey. "Development and Use of Parallel Hybrid Electric Vehicle Model with Suitable Modifications and Break-even Analysis." Int J Sci Res 4 (2015): 1281-1284

[7] Mendler, Edward Charles. "Hydraulic hybrid power system." U.S. Patent Application No. 12/451,690.

[8] Zeng, Xianwu. "Improving the energy density of hydraulic hybrid vehicle (HHVs) and evaluating plug-in HHVs." (2009)

\section{Author Profile}

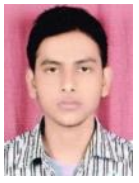

Mayank Giri is pursuing his B.Tech in Mechanical Engineering from NIT Raipur and presently is in his third year of undergraduate study (2014-18). He is an automobile enthusiast and his fields of interest are sustainable energy, artificial intelligence, driverless technology, efficiency improvement and utilization, hybrid vehicles. Currently he is an active member of SAE NIT Raipur.

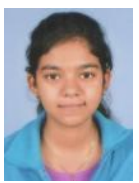

Renuka Sahu is pursuing her B.Tech in Mechanical Engineering from NIT Raipur and is presently in Third year of undergraduate study(2014-2018). Her interests include field of sustainable energy, automotive engineering and hybrid vehicles. Currently she is an active member of SAE NIT Raipur. 